\title{
Design and fabrication of rotor lateral shifting in the axial-flux permanent-magnet generator
}

\author{
Nurma Sari ${ }^{1,2}$, Gatut Yudoyono ${ }^{1}$, Ali Yunus Rohedi ${ }^{1}$, Yono Hadi Pramono ${ }^{1}$ \\ ${ }^{1}$ Department of Physics, Institut Teknologi Sepuluh Nopember, Surabaya, Indonesia \\ ${ }^{2}$ Physics Study Program, University of Lambung Mangkurat, Lampung, Indonesia
}

\begin{tabular}{l} 
Article Info \\
\hline Article history: \\
Received Jan 29, 2021 \\
Revised Jul 16, 2021 \\
Accepted Aug 4, 2021 \\
\hline Keywords: \\
Axial-flux permanent-magnet \\
NN \\
NS \\
Rotor lateral shifting \\
Single-stator double-rotor
\end{tabular}

Single-stator double-rotor

\begin{abstract}
The development of axial-flux permanent-magnet (AFPM) machines has become a mature technology. The single-stator double-rotor (SSDR) AFPM structure has advantages on the compactness and the low up to medium power applications so the microscale size and low-cost applications are reachable to be designed. The research main objectives are designing and manufacturing the lateral shifting from the north poles of the first rotor face the north poles of the second rotor (NN) to the north poles of the first rotor face the south poles of the second rotor (NS) categories as well as finding the best performance of the proposed method and implementing in a low cost and micro-scale AFPMG. The novel lateral shifting on the one of the rotors shows performance at $19.2^{0}$ has the highest efficiency at $88.39 \%$ during lateral shifting from $\mathrm{N}-\mathrm{N}\left(0^{0}\right)$ to $\mathrm{N}-\mathrm{S}\left(36^{0}\right)$ on rotor2.
\end{abstract}

This is an open access article under the CC BY-SA license.

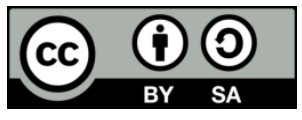

\section{Corresponding Author:}

Yono Hadi Pramono

Department of Physics, Institut Teknologi Sepuluh Nopember

Kampus ITS Sukolilo-Surabaya 60111 Indonesia

Email: yonohadipramono@gmail.com; yono@physics.its.ac.id

\section{INTRODUCTION}

Development of permanent-magnet (PM) generators from magnetic interactions between permanent magnets, currents, and various magnetic materials are successfully converting rotational mechanical energy into electrical energy for a wide variety of applications [1]. Compared to other types of magnetic machines, PM machines have several benefits for miniaturized or microscale applications. The magnetic interactions governing the machine operation scale independently with size. Power generator electric machinery designs are being made as compact and light as possible and also considering its size and weight [2]. Moreover, PM generators advantages are having high-torque and low-speed applications [3]-[7]. PM generators are widely used as an alternative of non chemical batteries power source research propagates rapidly in recent years and mainly motivated by the needs of power requirements especially in low-power consumption and applications. The design of a high-speed $100 \mathrm{~W}$ generator suitable for use with a gas turbine was developed by [8] and its losses caused by the high frequency operation are compensated by optimizing the winding and the stator core material.

For the last 40 years, as development of axial-flux permanent-magnet (AFPM) machines rapidly and widely spread research effort and becoming a mature technology [9], also become very attractive due to its highly-efficient machines for distributed power generation systems [2], [10]. and also due to other benefits compared to the slotted radial flux configuration such as shorter stack length, high torque density achievement and high efficiency [11]-[14]. The AFPM machines can be classified into three types which are single stator single-rotor (SSSR), single-stator double-rotor (SSDR), double-stator single-rotor (DSSR), or multi-stator multi-rotor (MSMR) [6], [15]. Many research of AFPM machines mainly focuses on in the 
aspects of construction, features, electromagnetic and thermal modelling, simulation, analysis, design, materials, and manufacturing [16]. Another research are focusing on the effect back iron on the efficiency of the generator [17] and the testing of the airgap value [18]. The structure with two rotors and one stator (SSDR AFPM) machine introduced by Profumo et al. is one of the promising solution for both induction and synchronous machines due to the two rotors can rotate at different speeds, therefore the motor is able to act as a mechanical differential. Moreover, the AFPM motor with two rotors is highly compacted form [19]. The SSDR AFPM structure has advantages on high power density, the rotation of fans around the stators winding is working as a cooling fan for the windings and also applied from the low up to medium power applications [15], [20].

TORUS development and arrangement of axial modern machines by [21]-[23] made simpler toroidal winding and allowing the windings moves along the stator to achieve spatial windings automatically. Commonly there are two categories of SSDR AFPM machine based on the flux directions inside the machine, the NN type TORUS [15], [24], [25] and the NS type TORUS [15], [26] which are showing the north poles of the first rotor face the north poles of the second rotor and the north poles of the first rotor face the south poles of the second rotor respectively. Meanwhile, Omrani et al. [27] studied that independent bearing and axis of double sided disc type permanent magnetic motor are able to rotate two different loads at equal velocities without encountering stability problems and will lead increasing the usages of the motor.

With advantages of PM generators [1] and compactness of SSDR type of AFPM [19], the microscale size applications are possibly designed. In this research, our main objectives are designing and manufacturing the lateral shifting from NN to NS categories as well as finding the best performance of the proposed method and implementing in a low cost and microscale axial-flux permanent-magnet generator (AFPMG). We designed and fabricated the AFPMG consist of one stator between two rotors (SSDR type) to generate high efficient AFPM generator. Performance analysis is presented to show the reach of our research in this particular design. The objective of this paper is to design and implement a high performance of SSDR AFPM. To this purpose, we have introduced a novel rotor lateral shifting to one of the two rotors to improve the efficiency of the state-of-the-art NN and NS categories in the SSDR types. Specifically, we have:

a. Composed independent rotor lateral shifting from $\mathrm{N}-\mathrm{N}\left(0^{\circ}\right)$ to $\mathrm{N}-\mathrm{S}\left(36^{\circ}\right)$ on rotor 2 .

b. Introduced a novel approach for the rotor best position at $19.2^{\circ}$ with the highest efficiency at $88.39 \%$ during lateral shifting method.

c. Provided a compact and a low cost of SSDR AFPM generator with high efficiency.

\section{RESEARCH METHOD}

The design of the SSDR type of AFPM generator consists of the components and materials as shown in Table 1. Rotor and its permanent magnet are parts of the AFPM generator and structured by turns of the different poles in the circular form. Rotor plates material made from aluminium and the thikness is $0.3 \mathrm{~cm}$. We designed rotors with diameter $25 \mathrm{~cm}$ and made from Neodymium material in the form of circular (with diameter $5 \mathrm{~cm}$ and width $1 \mathrm{~cm}$ ). An angle $36^{\circ}$ for each magnet was symmetrically arranged with poles oppositely to bring N-S-N-S shifting. This arrangement implies rotor magnetism varied from N-N $\left(0^{\circ}\right)$ to $\mathrm{N}-\mathrm{S}\left(36^{\circ}\right)$. Figures $1(\mathrm{a})$ and $1(\mathrm{~b})$ shows the rotor design and its implementation.

The stator desain as shown on the Table 1 which are consisted of 12 coils with diameter is $20 \mathrm{~mm}$, outer coils diameter is $75 \mathrm{~mm}$, outer coils width is $60 \mathrm{~mm}$, and the number of coils turns are 1000. The stator design was marked with certain combination as to make it easier during the electrical circuit to generate three phase electrical source. The design and its implementation can be clearly seen in the Figures 2(a) and 2(b).

Table 1. The design of the DSSR type of AFPM

\begin{tabular}{cc}
\hline Components & Features \\
\hline Coils diameter $(\mathrm{mm})$ & 20 \\
Outer coils diameter $(\mathrm{mm})$ & 75 \\
Outer coils width $(\mathrm{mm})$ & 60 \\
Phase & 3 \\
Number of coils turns & 1000 \\
Number of coils & 12 \\
Wire diameter $(\mathrm{mm})$ & 0.7 \\
Magnet type & Neodymium $\left(\mathrm{Nd}_{2} \mathrm{Fe}_{14} \mathrm{~B}\right)$ \\
Magnet shape & Circular \\
Number of magnets & 20 \\
Magnets diameter $(\mathrm{mm})$ & 50 \\
Magnets thickness $(\mathrm{mm})$ & 10 \\
Core type & Axial \\
Air gap between rotor and stator $(\mathrm{mm})$ & 1.5 \\
\hline
\end{tabular}

Int J Elec \& Comp Eng, Vol. 12, No. 1, February 2022: 141-149 


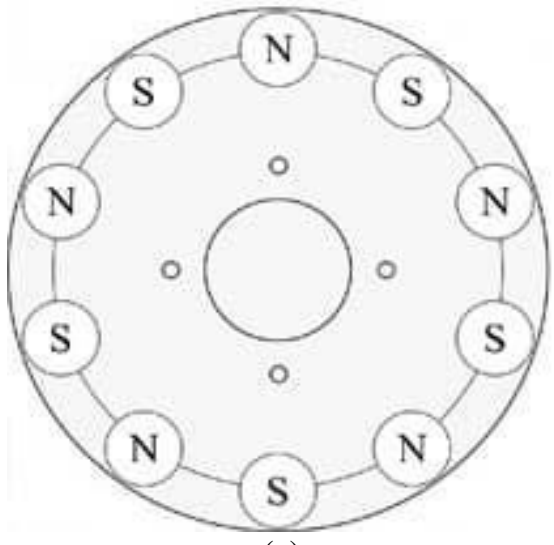

(a)

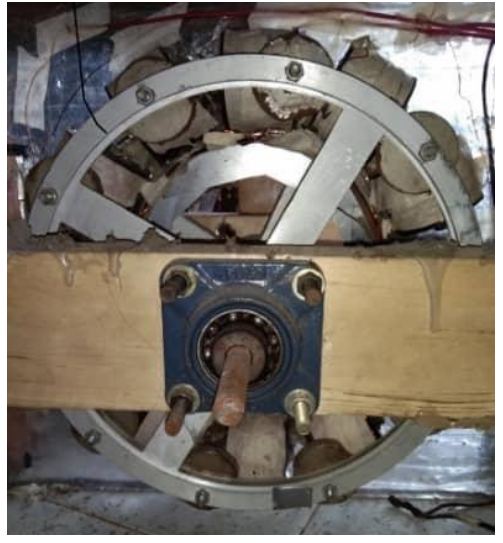

(b)

Figure 1. Rotor with permanent-magnets attached, (a) design, (b) its implementation

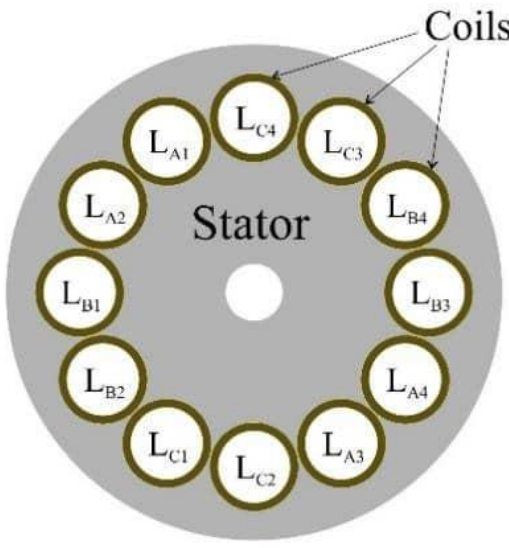

(a)

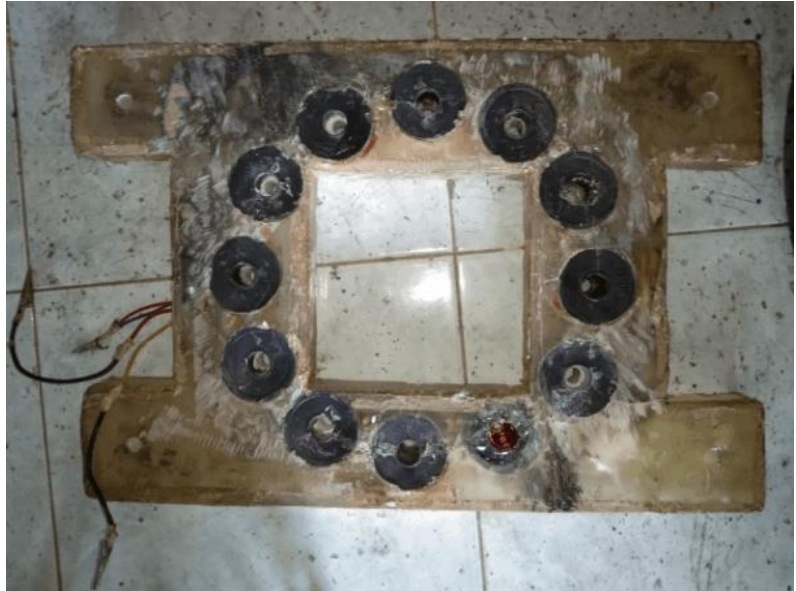

(b)

Figure 2. Stator with coils attached, (a) design, (b) its implementation

The magnetic flux $\left(\varphi_{m}\right)$ calculation in which measuring the total magnetic field $(B)$ that passes through a given surface area $(A)$. The formula of the magnetic flux as (1):

$$
\varphi_{m}=B A
$$

Meanwhile, the number of the magnetic flux at which the normal component of field lines passing through a given surface area, thus the magnetic flux formula become:

$$
\begin{aligned}
\varphi_{m} & =B \cdot \hat{n} A \\
\varphi_{m} & =B A \cos \theta
\end{aligned}
$$

where $\hat{n}$ is the normal component and $\theta$ is the angle between the magnetic field lines and the normal (perpendicular) to the surface area. However, there is back emf that existed during running motor due to the consisting of a coil turning in the magnetic field and opposing the voltage powering and driving the motor [28].

The angle of each coil is $30^{\circ}$ and classified in three different marked with series connections generating one phase each. With $\mathrm{R}_{1}=\mathrm{R}_{2}=\mathrm{R}_{3}$, amplitude and the phase (output sinusoidal voltages are $120^{\circ}$ ) are identically same see in Figure 3. The windings combination on the coil and electric circuit equivalent to generate three phase machine of the marked Figure 2 can be clearly seen on Figure 3. 
The AFPM Generator was designed with lateral shifting on the one of the rotor and then investigating the highest efficiency of the machine as shown in Figure 4. We designed double rotor and the one stator in between as it has higher efficiency compared to single rotor [29]. Both rotors and stator are coreless and connected in the same axis so technically easier to manufacture [30]. The rotor lateral shifting was observed from $0^{\circ}$ to $36^{\circ}$ matching the angle between both magnets curve length. The efficiency was calculated by the load of $\delta$ connected to three phase generator output. Total power output was measured from the current and voltage of $\delta$. Meanwhile, total power input measurement was gotten from the motor rotation powered by direct current (DC) power supply.

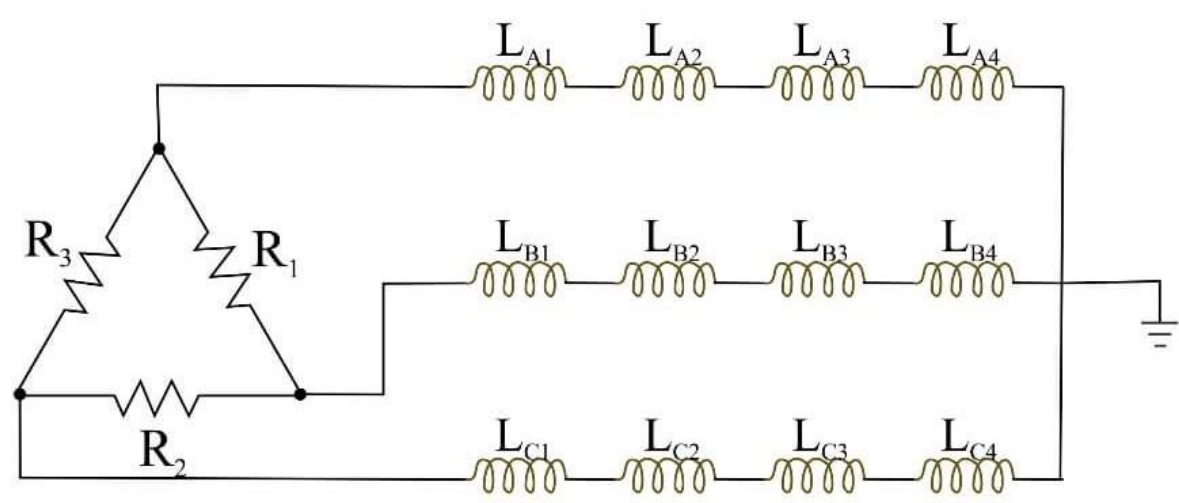

Figure 3. Three phase machine generated by Figure 2 marked configuration and the electric circuit equivalent

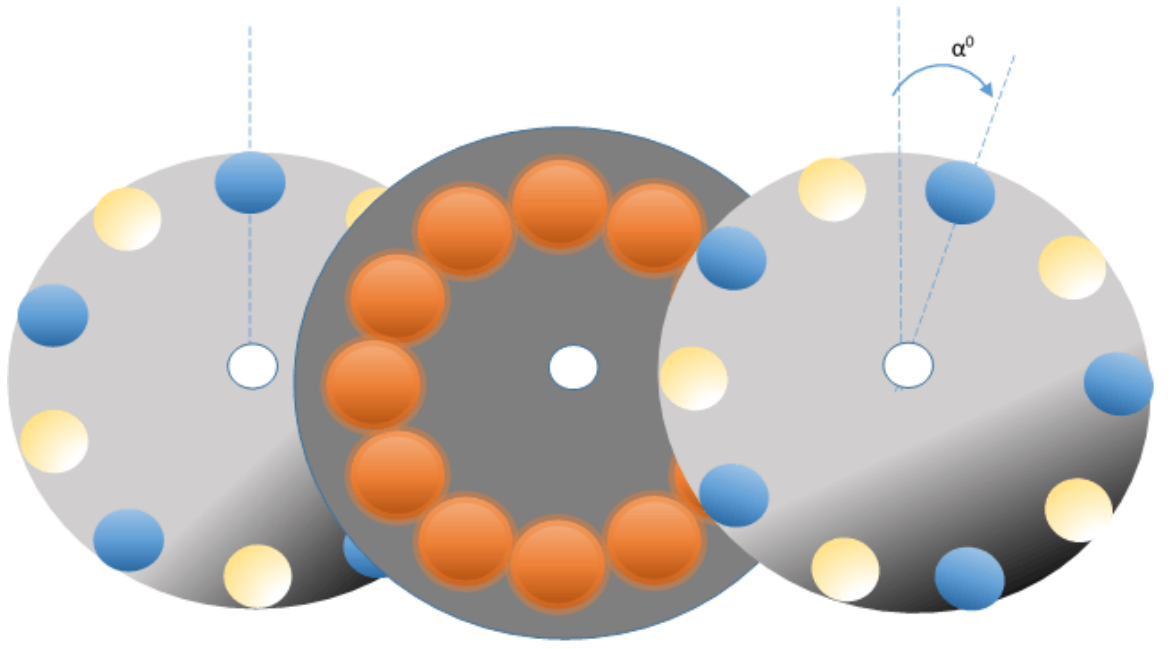

Figure 4. Schematic design of the lateral shifting of $\alpha$ (between two rotors)

We test our approach by connecting AFPM generator $(G)$ prototype to electronic circuit and measuring the current $(A)$ and the voltage $(V)$ as shown in Figure 5. By measuring current and voltage, power out can be calculated and then compared to the generator for calculating efficiency of the generator. Implementation of the circuit can be clearly seen on Figure 6. Power out calculation was taken from the generator resistance, current, the load resistance and its voltage:

$$
P_{\text {out }}=I^{2} R_{g}+V_{\text {out }} I
$$

where $P_{\text {out }}$ is power consumption, $I$ is the flowing current in the circuit, $R_{g}$ is the generator resistance and $V_{\text {out }}$ is the output voltage taken from the load. Eficiency of proposed AFPMG should be calculated as (5),

$$
\eta=\left(P_{\text {out }} / P_{\text {in }}\right) \times 100 \%
$$


where the input power $\mathrm{P}_{\text {in }}$ is determined from the input voltage and current on DC motor as a generator drive. Total mechanical losses in this case will not be discussed, because they are included in the measured output power. We only consider how much input is supplied and how much power is generated to get the value of efficiency.

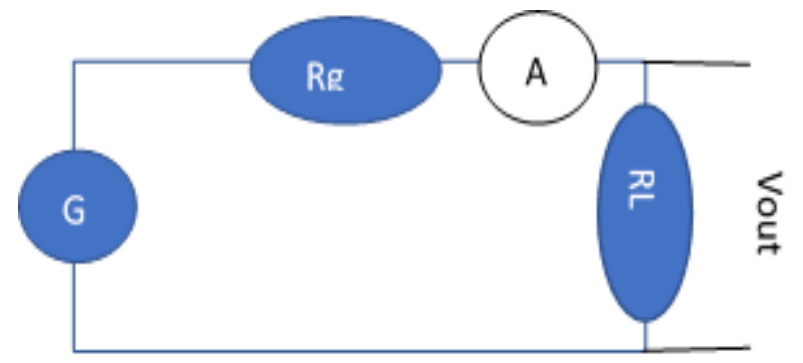

Figure 5. Electronic circuit with load for testing power efficiency

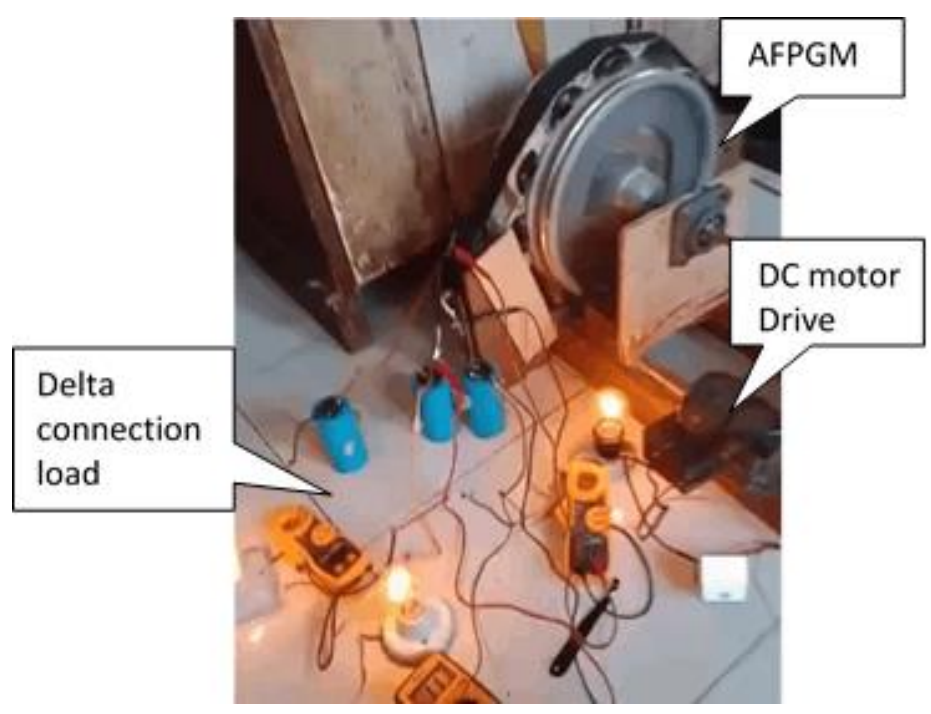

Figure 6. Implementation of the circuit from Figure 5

\section{RESULTS AND DISCUSSION}

Figure 7 shows the sinusoidal wave form that attached to the oscilloscope during experiment as shown in Figure 6 . The three phase angles are $120^{\circ}$ each. It is also indicating that the system is working well. Figures 8(a) dan 8(b) are both in the symmetrical condition with $\theta=0$ applied in (3). In Figure 8(a), there are no field lines passing through the surface; however, there are small magnetic flux from both sides of the rotors and reducing back emf, resulting small power output due to small $\mathrm{V}$ and I. This reduced back emf implicates voltage frees up to push the motor to operate at higher output speeds so the RPM is reaching maximum due to reducing resistance from the back emf since no magnetic fields in between both rotors. Meanwhile, Figure 8(b) is having highest magnetic flux since all field lines passing through the given surface but the back emf is also fully emerged, limiting its rotation (RPM is decreasing) and resulting power output is higher than on the Figure 8(a).

The measured efficiency and RPM of the rotor lateral shifting show that during the first structure which are $\alpha=0^{\circ}$ or N-S-N-S for rotor ${ }_{1}$ and N-S-N-S for rotor $_{2}$ on the pole condition is $20.21 \%$ due to flux from the same magnet polar will be annihilated each other and implied to only small flux change inducted emf on the coil in Figure 8(a). Small emf detected on the back and torque become lighter that made RPM around 1300 and finally only small amount of power consumed. Meanwhile, during the second structure which are $\alpha=36^{\circ}$ or N-S-N-S for rotor ${ }_{1}$ and S-N-S-N for rotor 2 , all flux from both magnets induct emf on the coil in Figure 8(b). It has higher efficiency which is 68,19\%. However, this conditions made RPM speed is decreasing since larger emf detected on the back and torque become heavier and larger power consumed. 


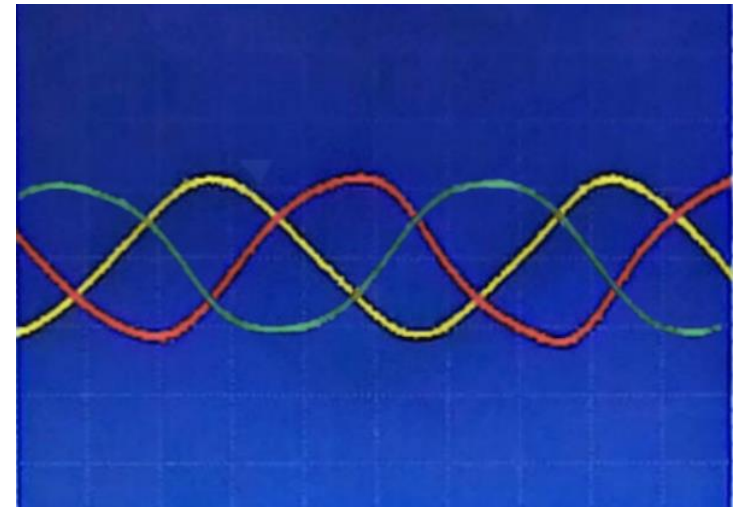

Figure 7 . The three sinusoidal wave form produced by the three-phase voltage of the generator

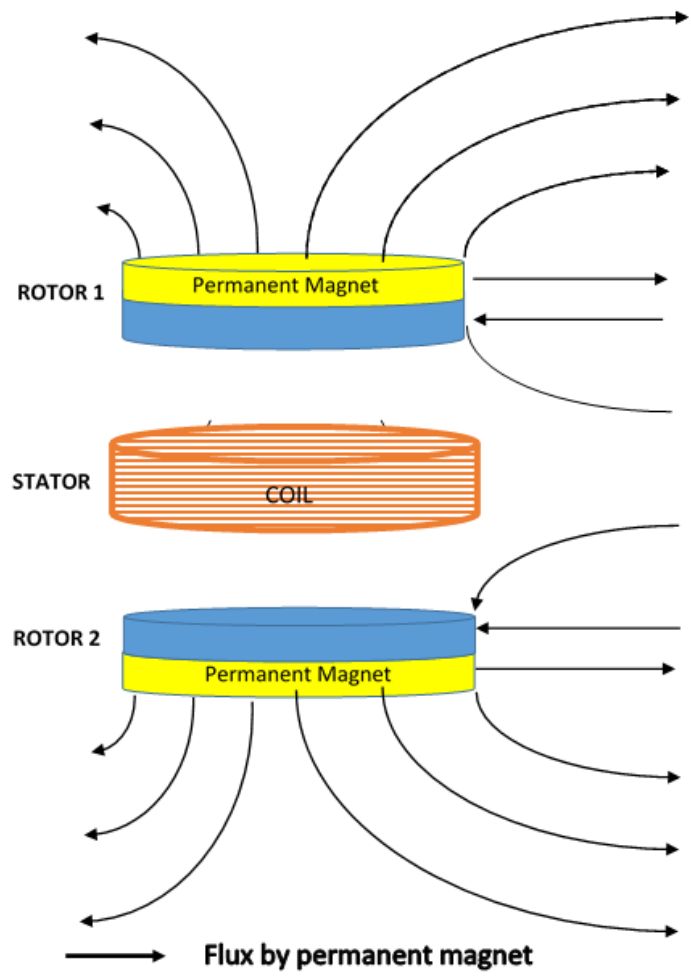

(a)

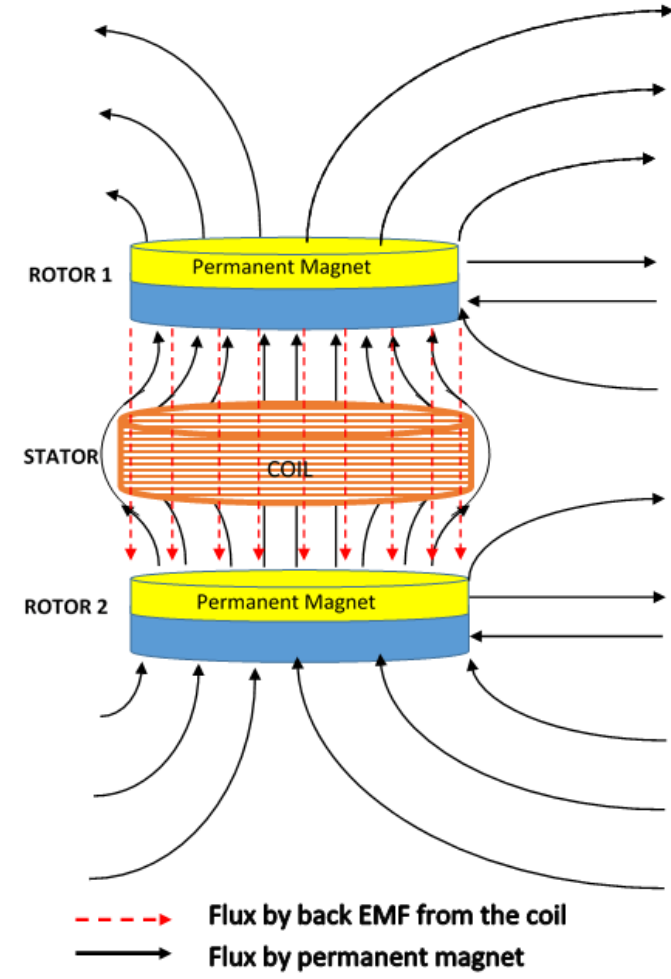

(b)

Figure 8. Flux produced by permanent magnets, (a) first structure, (b) second structure

Figure 9 (which is the proposed structure) shows asymmetrical condition with $\theta \neq 0$ and the back EMF is partially passing through the given surface area (back emf is not in the maximum condition). This condition makes smaller torque generated but the number of field lines is as same as before resulting higher efficiency. During lateral shifting position at $\alpha=19.2^{\circ}$, the flux induction to the coils is similar to the flux at $\alpha=36^{\circ}$ and we found that the significant difference is the decreasing of back emf. As shown in Figure 9, the back emf always perpendicular to the coil so it gave small contributions to both rotor braking and resulting to the smaller power consumption with 864 RPM.

Figure 10 shows efficiency and RPM responses during rotor rotation from $\alpha=0^{\circ}$ to $\alpha=36^{\circ}$. The reduced back emf shows the maximum RPM as shown in Figure 8(a) and than the speed keep decreasing as the back emf is emerging until the back EMF is also fully emerged in Figure 8(b), limiting the rotation and RPM is minimum. In general, the trend of the RPM as shown in Figure 10 is decreasing during the rotation (the lateral shifting). Meanwhile, the efficiency of the proposed AFPMG was varied depend on the lateral shifting procedure and showing rotor lateral shifting performance at $19.2^{\circ}$ reach its peak at $88.39 \%$. 


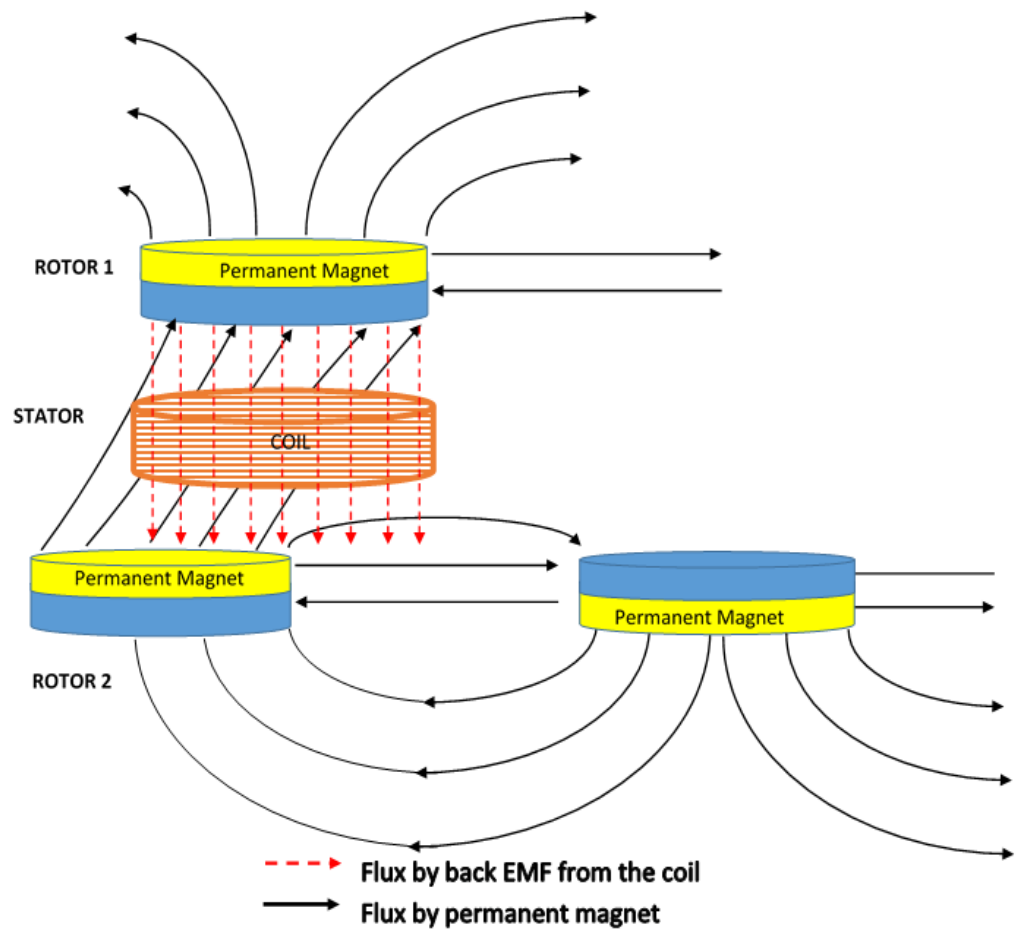

Figure 9. Flux magnet at $\alpha^{\mathrm{o}}$ (proposed structure)

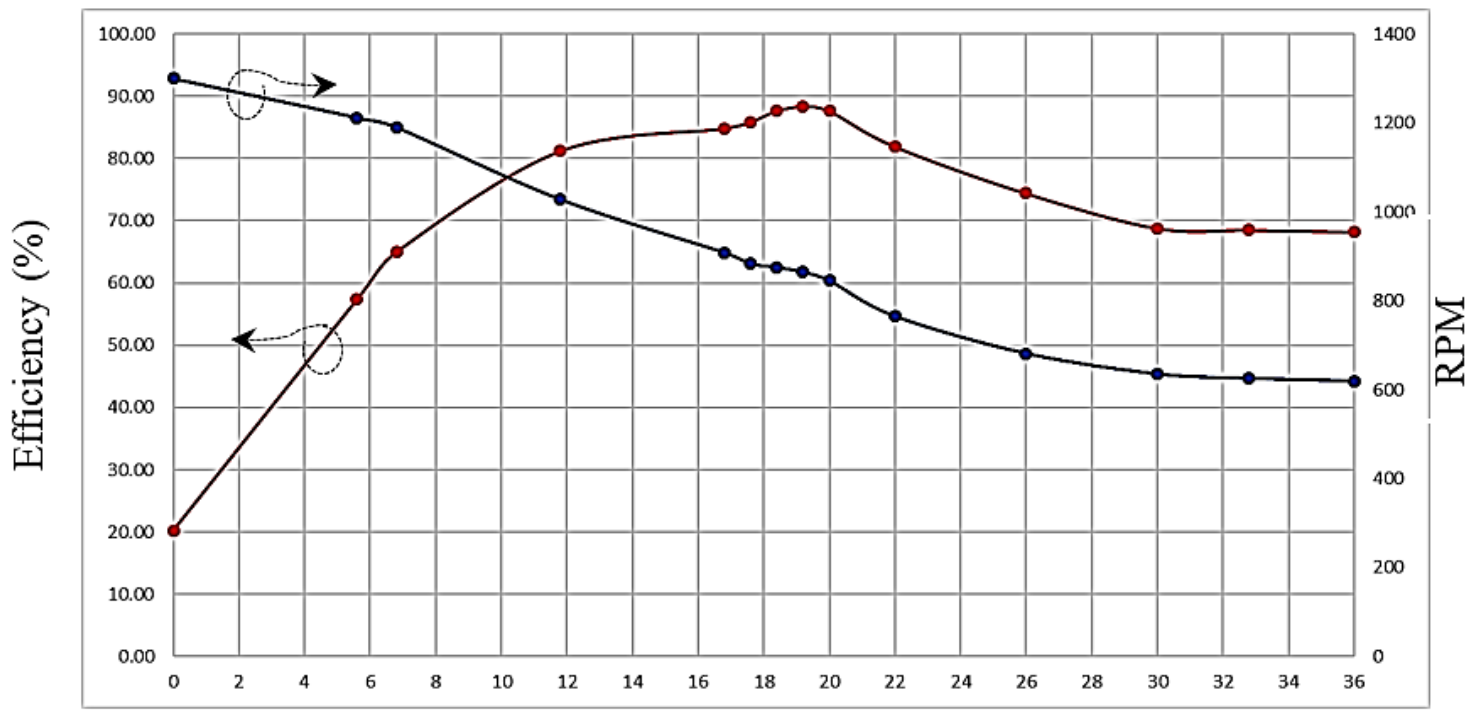

Angle of the lateral shift on the rotor $\left(\alpha^{\circ}\right)$

Figure 10. Efficiency (red line) and RPM (black line) responses due to rotor lateral shifting on the rotor from $^{2}$ $0^{\circ}$ to $36^{\circ}$

\section{CONCLUSION}

In conclusion, we have proposed a novel rotor lateral shifting to one of the two rotors to improve the efficiency of the state-of-the-art NN and NS categories in the SSDR types. Our independent rotor lateral $^{2}$ shifting approach are shifted from $\mathrm{N}-\mathrm{N}\left(0^{\circ}\right)$ to $\mathrm{N}-\mathrm{S}\left(36^{\circ}\right)$. Our approach resulted performance at $19.2^{\circ}$ with the best efficiency at $88.39 \%$ during lateral shifting. It is has been manufactured a compact and a low cost of SSDR AFPM generator with high efficiency. In the future, we would like to implement our approach with a new shape design of the coil to increase the flux and the power generator as well as maintain its efficiency. 


\section{ACKNOWLEDGEMENTS}

Nurma Sari is supported by Doctoral Scholarship for Lecturer of Indonesian Endowment Fund for Education (BUDI-DN of LPDP Indonesia).

\section{REFERENCES}

[1] O. Cugat, J. Delamare, and G. Reyne, "Magnetic micro-actuators and systems (MAGMAS)," IEEE Transactions on magnetics, vol. 39, no. 6, pp. 3607-3612, Nov. 2003, doi: 10.1109/TMAG.2003.816763.

[2] F. Caricchi, F. Crescimbini, O. Honorati, G. L. Bianco, and E. Santini, "Performance of coreless-winding axial-flux permanentmagnet generator with power output at $400 \mathrm{~Hz}, 3000 \mathrm{r} / \mathrm{min}$," IEEE Transactions on Industry Applications, vol. 34, no. 6, pp. 1263-1269, Dec. 1998, doi: 10.1109/28.739003.

[3] M. K. Pandey, A. Tripathi, and B. Dwivedi, "FEA of a high efficiency brushless DC motor design," International Journal of Applied Engineering Research, vol. 12, no. 21, pp. 11417-11423, 2017.

[4] S. S. Dudhe and A. G. Thosar, "Mathematical modelling and simulation of three phase BLDC motor using MATLAB/Simulink," Int. Journal of Advances in Engineering and Technology, vol. 7, no. 5, pp. 1426-1433, 2014.

[5] S. V. Gadewar and A. M. Jain, "Modelling and simulation of three phase BLDC motor for electric braking using MATLAB/ Simulink," Int. J. of Electrical, Electronics And Data Communication, vol. 5, no. 7, pp. 48-53, 2017.

[6] M. J. Yang, H. Jhou, B. Ma, and K. Shyu, "A cost-effective method of electric brake with energy regeneration for electric vehicles," IEEE Transactions on Industrial Electronics, vol. 56, no. 6, pp. 2203-2212, Jun. 2009, doi: 10.1109/TIE.2009.2015356

[7] D. T. Kordkandi, H. K. Gardeshi, and H. Torkaman, "An Improved method to control the speed and flux of PM-BLDC motors," in The 6th Power Electronics, Drive Systems and Technologies Conference (PED-STC2015), Feb. 2015, pp. 639-644, doi: 10.1109/PEDSTC.2015.7093349.

[8] C. Zwyssig, J. W. Kolar, W. Thaler, and M. Vohrer, "Design of A 100 W, 500000 RPM permanent-magnet generator for mesoscale gas turbines," in Fourtieth IAS Annual Meeting. Conference Record of the 2005 Industry Applications Conference, vol. 1. 2005, pp. 253-260, doi: 10.1109/IAS.2005.1518318.

[9] F. G. Capponi, G. De Donato, and F. Caricchi, "Recent Advances in axial-flux permanent-magnet machine technology," IEEE Transactions on Industry Applications, vol. 48, no. 6, pp. 2190-2205, Dec. 2012, doi: 10.1109/TIA.2012.2226854.

[10] M. Aydin, S. Huang, and T. Lipo, "Axial flux permanent magnet disc machines: a review," in Conf. Record of SPEEDAM, vol. 8, 2004, pp. 61-71

[11] A. Cavagnino, M. Lazzari, F. Profumo, and A. Tenconi, "A comparison between the axial flux and the radial flux structures for PM synchronous motors," IEEE transactions on industry applications, vol. 38, no. 6, pp. 1517-1524, 2002, doi: 10.1109/TIA.2002.805572.

[12] J. M. Seo, S. Rhyu, J. Kim, J. Choi, and I. Jung, "Design of axial flux permanent magnet brushless DC motor for robot joint module," in The 2010 International Power Electronics Conference-ECCE ASIA-. IEEE, 2010, pp. 1336-1340, doi: 10.1109/IPEC.2010.5544557

[13] B. Guo and Y. Huang, "A fast analytic model of axial flux permanent magnet machines with static/dynamic axis eccentricity," Journal of Magnetics, vol. 21, no. 4, pp. 554-560, 2016, doi: 10.4283/JMAG.2016.21.4.554.

[14] O. Bouaziz, I. Jaafar, and F. B. Ammar, "Performance analysis of radial and axial flux PMSM based on 3d FEM modeling," Turkish Journal of Electrical Engineering and Computer Sciences, vol. 26, no. 3, pp. 1587-1598, 2018, doi: 10.3906/elk-170868.

[15] S. Amin, S. Khan, and S. S. H. Bukhari, "A comprehensive review on axial flux machines and its applications," in 2019 2nd International Conference on Computing, Mathematics and Engineering Technologies (iCoMET). IEEE, 2019, pp. 1-7, doi: 10.1109/ICOMET.2019.8673422.

[16] S. Kahourzade, A. Mahmoudi, H. W. Ping, and M. N. Uddin, "A comprehensive review of axial-flux permanent-magnet machines," Canadian journal of electrical and computer engineering, vol. 37, no. 1, pp. 19-33, 2014, doi: 10.1109/CJECE.2014.2309322.

[17] H. Gör and E. Kurt, "Effects of back iron components on efficiency and generated power for new wind energy generators," Electric Power Components and Systems, vol. 46, no. 10, pp. 1105-1122, 2018.

[18] H. Gör and E. Kurt, "Preliminary studies of a new permanent magnet generator (PMG) with the axial and radial flux morphology," International Journal of Hydrogen Energy, vol. 41, no. 17, pp. 7005-7018, 2016.

[19] F. Profumo, Z. Zhang, and A. Tenconi, "Axial flux machines drives: A new viable solution for electric cars,” IEEE Transactions on Industrial Electronics, vol. 44, no. 1, pp. 39-45, 1997, doi: 10.1109/41.557497.

[20] T. Kwang, M. L. M. Jamil, and A. Jidin, "Improved magnetic behavior of hemicycle pm motor via stator modification," International Journal of Electrical and Computer Engineering (IJECE), vol. 10, no. 3, pp. 3323-3332, 2020, doi: 10.11591/ijece.v10i3.pp3323-3332.

[21] P. Campbell, "Principles of a permanent-magnet axial-field DC machine," in Proceedings of the Institution of Electrical Engineers, vol. 121, no. 12, 1974, pp. 1489-1494.

[22] E. Spooner and B. Chalmers, "TORUS: A slotless, toroidal-stator, permanent-magnet generator," in IEE Proceedings B (Electric Power Applications), vol. 139, no. 6, 1992, pp. 497-506

[23] P. Evans and J. Eastham, "Slotless-disc alternator with ac-side excitation," in IEE Proceedings B (Electric Power Applications), vol. 130 , no. 6,1983 , pp. 399-406

[24] R. Hill-Cottingham, P. C. Coles, D. Rodger, and H. C. Lai, "Finite element modelling of an axial flux PM machine," in Second International Conference on Power Electronics, Machines and Drives (PEMD 2004), vol. 2, 2004, pp. 552-555, doi: 10.1049/cp:20040347.

[25] A. Walker, "Automotive integrated starter generator," in Second International Conference on Power Electronics, Machines and Drives (PEMD 2004), vol. 1, pp. 46-48, doi: 10.1049/cp:20040257.

[26] T. Nakata, N. Takahashi, and K. Uehara, "Analysis of magnetic characteristics of a brushless DC motor taking into account the distribution of magnetization," IEEE Transactions on Magnetics, vol. 22, no. 5, pp. 1084-1086, Sep. 1986, doi: 10.1109/TMAG.1986.1064365. 
[27] S. Omrani, A. Darabi, and H. Mizan, "A new two separate rotor axial flux permanent magnet motor; analysis and performance comparison," in 2018 International Conference of Electrical and Electronic Technologies for Automotive, 2018, pp. 1-5, doi: 10.23919/EETA.2018.8493176.

[28] W. Hua, M. Cheng, Z. Q. Zhu, and D. Howe, "Analysis and optimization of back emf waveform of a flux-switching permanent magnet motor," IEEE Trans. Energy Convers., vol. 23, no. 3, pp. 727-733, Sep. 2008, doi: 10.1109/TEC.2008.918612.

[29] E. Erturk, S. Sivrioglu, and F. C. Bolat, "Analysis model of a small scale counter-rotating dual rotor wind turbine with double rotational generator armature," International Journal of Renewable Energy Research (IJRER), vol. 8, no. 4, pp. 1849-1858, Dec. 2018.

[30] H. Gor and E. Kurt, "Waveform characteristics and losses of a new double sided axial and radial flux generator," International Journal of Hydrogen Energy, vol. 41, no. 29, pp. 12512-12524, 2016.

\section{BIOGRAPHIES OF AUTHORS}

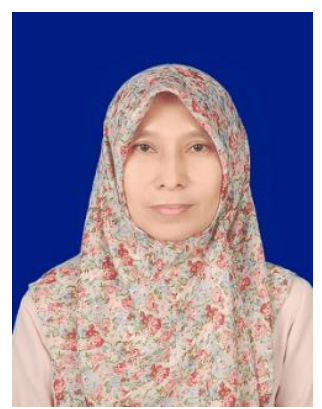

Nurma Sari (D) 8I SC P received the Bachelor's degree in Physics (1996) from University of Diponegoro (UNDIP) and a masters degree in Physics (2007) specializing in waveguide antenna from Institut Teknologi Sepuluh Nopember (ITS). She is currently reading for a Dr degree at Institut Teknologi Sepuluh Nopember (ITS), Indonesia, funded by BUDI-DN LPDP Indonesia. Her interdisciplinary research interests focus on applying electromagnetics, applying optics and waveguide antenna. She can be contacted at email: nurmasari01@ulm.ac.id.

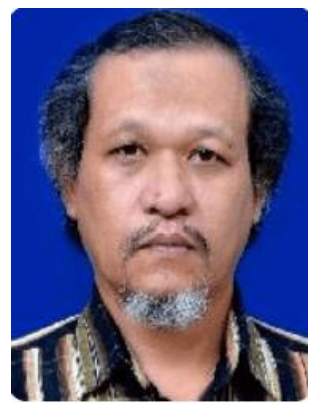

Gatut Yudoyono (D) Bd SC P received the Bachelor's degree in Physics (1988) from Universitas Airlangga (UNAIR), Master Engineering degrees from Optoelectronics and Laser Applications (OEAL) Indonesia University (UI) in 1997 and PhD degree in physics (2017) from Institut Teknologi Sepuluh Nopember specializing in optical materials, especially titania material. His interdisciplinary research interests focus on optics and photonics, laser applications, optical sensing, solar cells and optical communications. He can be contacted at email: gyudoyono@physics.its.ac.id.

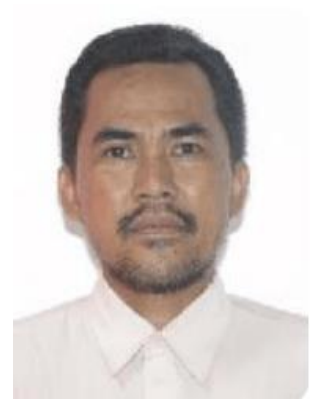

Ali Yunus Rohedi (D) I8 SC P received the Bachelor's degree from Department of Physics, Institut Teknologi Sepuluh Nopember (ITS) Surabaya in 1991, and Master Engineering degrees from Optoelectronics and Laser Applications (OEAL) Indonesia University (UI) in 1997 respectively. Since 1992, he have been working at Department of Physics, Institut Teknologi Sepuluh Nopember (ITS) in Surabaya. His current research of interest include optical and microwave communications, nonlinear optical phenomena, and developing "smart technique" for solving Problems of Mathematics. He can be contacted at email: rohedi@physics.its.ac.id.

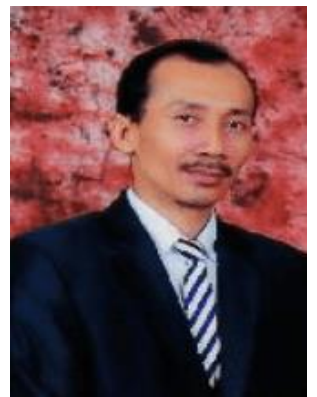

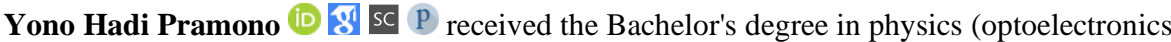
and applied electromagnetics) from Institut Teknologi Sepuluh Nopember (ITS), Surabaya, Indonesia, in 1991. Since April 1991 he has been a Research Associate of the Department of Physics (Optoelectronics). Institut Teknologi Sepuluh Nopember (ITS), Surabaya, Indonesia. He received M. Eng. degree in Electrical and Electronic Engineering from Osaka Prefecture University, Osaka, Japan, in 1997. From April 1997 to March 2000, he has studying microwave engineering, optical-wave transmission line and integrated optics under Ph.D. program in the Department of Electrical and Electronic System, Osaka Prefecture University, Osaka, Japan. He can be contacted at email: yonohadipramono@gmail.com. 